\title{
Modulating Effects of Pentoxifylline on Cytokine Release Syndromes
}

\author{
F.U.Schade and P.Zabel
}

\section{Introduction}

Tumor necrosis factor- $\alpha$ (TNF) has been identified as the most important mediator of septic shock and cachexia in animals and humans. Moreover, TNF plays a major role in the pathophysiological events of many other infectious and immunological diseases. Therefore, drugs interfering with the formation of TNF may have beneficial effects in these clinical circumstances.

Among the various compounds elaborated by macrophages in response to endotoxins, prostaglandins have been recognized to contribute to the regulation of cytokine biosynthesis $[1,2]$. TNF synthesis is negatively controlled by prostaglandin $\mathrm{E}$ (PGE), most probably by increases in intracellular cAMP. This finding has led to the hypothesis that endogenously formed PGE limits the extent of TNF synthesis by macrophages. In agreement with this, it has been found that inhibition of prostaglandin synthesis by indomethacin or aspirin results in increased TNF production [3]. Based on the above results, the assumption seemed reasonable that intracellular increases in cAMP by inhibition of phosphodiesterases (PDEs) would also lead to attenuation of TNF synthesis and, hence, should be of benefit in the syndromes described above. In our laboratories and clinic, a PDE inhibitor which is clinically in wide use, pentoxifylline (3,7-dimethyl-1-(5-oxo-hexyl)-xanthine, POF), has been tested with regard to its effects on cytokine production and endotoxin lethality. Pentoxifylline is a drug of known hemorrheological activity. Its effects were supposed to be based on its ability to increase erythrocyte flexibility, to reduce blood viscosity and filterability, and to increase capillary flow in several diseases. It has been used clinically for therapy of patients with various types of vascular insufficiency particularly intermittent claudication [4].

\section{Pentoxifylline Inhibits Tumor Necrosis Factor Synthesis in Macrophage Cultures and in Lipopolysaccharide-Treated Mice}

The putative TNF inhibitory activity of POF was first tested in macrophage cultures stimulated with endotoxin (lipopolysaccharide, LPS; $100 \mathrm{ng} / \mathrm{ml}$ ) in the presence of POF. The results shown in Fig. 1 provide evidence that POF, over the whole concentration range of $3.1-50 \mu \mathrm{g} / \mathrm{ml}$, provided significant in- 
hibition on the formation of TNF by macrophages [5]. This finding is in agreement with the reported evidence of others that POF inhibited the formation of TNF mRNA in mouse peritoneal macrophages [6] and TNF released by human monocytes [7]. In order to further characterize the action of POF on TNF synthesis, its inhibitory activity was studied in mice [5]. TNF determinations were done in sera of D-galactosamine-sensitized mice challenged with endotoxin (LPS; $10 \mu \mathrm{g} /$ animal). The sera were sampled $1 \mathrm{~h}$ after LPS injection and TNF was quantified in an L-cell cytolysis assay. The values for TNF activity in serum are shown in Fig. 2. POF, at a dose of $50 \mathrm{mg} / \mathrm{kg}$ suppressed TNF formation completely and $10 \mathrm{mg} / \mathrm{kg}$ had pronounced inhibitory effects on the appearance of TNF in serum.

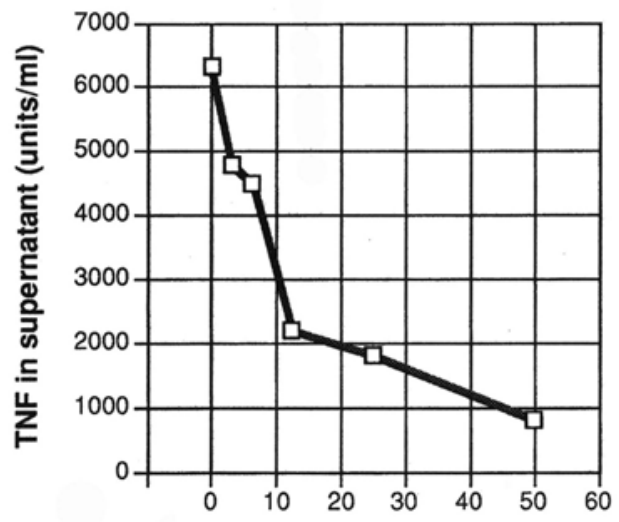

Amount of POF $(\mu \mathrm{g} / \mathrm{ml})$
Fig. 1. Inhibition of endotoxin (LPS)induced tumor necrosis factor $(T N F)$ synthesis in mouse peritoneal macrophages by pentoxifylline $(P O F)$. Values obtained with more than $10 \mu \mathrm{g} / \mathrm{ml}$ POF were significantly $(p<0.05)$ different from controls without POF

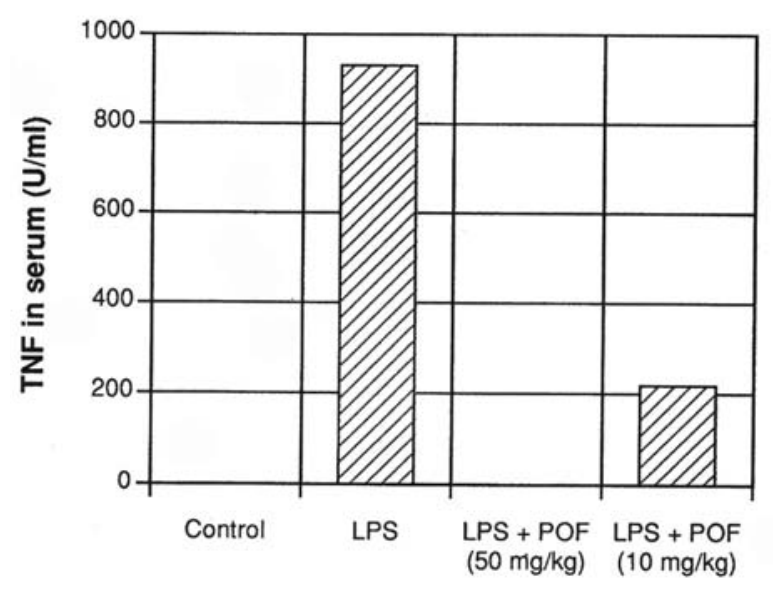

Fig. 2. Inhibition of endotoxin (LPS)-induced tumor necrosis factor $(T N F)$ synthesis in mice by pentoxifylline $(P O F)$ 


\section{Effects of Pentoxifylline on Endotoxin Lethal Toxicity}

Since the above data showed that POF was able to inhibit TNF synthesis in vitro and in vivo, it was suggested that xanthine derivatives potentially could be of benefit in endotoxin shock. Therefore, the effect of POF was investigated in several models of endotoxin shock [5, 8-10].

Pretreatment of normal mice with POF $(50 \mathrm{mg} / \mathrm{kg}) 1 \mathrm{~h}$ before the challenge with LPS $\left(500 \mu \mathrm{g} /\right.$ mouse, equivalent to a $\left.\mathrm{LD}_{50}\right)$ led to a significant increase in the survival rate compared to mice challenged with LPS alone. The overall survival rate increased from $50 \%$ to $90 \%$ (Fig. 3). Mice were rendered hypersensitive against endotoxin by a pretreatment with endotoxin $14 \mathrm{~h}$ before the challenge injection. Injection of $200 \mu \mathrm{g}$ LPS corresponded in LPS-hypersensitive mice to a $\mathrm{LD}_{80}$. Pretreatment of LPS-hypersensitive mice with POF $(50 \mathrm{mg} / \mathrm{kg})$ led to a survival rate of $90 \%$ (Fig. 3). Mice were rendered tolerant by a pretreatment with endotoxin $(80 \mu \mathrm{g}) 4$ day prechallenge. When these mice were challenged with a dose of LPS, otherwise corresponding to a $\mathrm{LD}_{50}$, and POF $(50 \mathrm{mg} / \mathrm{kg})$, a survival rate of $90 \%$ was observed (Fig. 3). As shown in Fig. 3, POF interferes with the lethal effects of LPS in normal, LPS-hypersensitive, and LPS-tolerant mice.

\section{Pentoxifylline Inhibits Endogenous Tumor Necrosis Factor Formation in Endotoxemia in Human Volunteers}

Based on the promising findings obtained in experimental animals we sought to approach the question as to the possibility that POF could be of benefit in humans too. A study, therefore, was designed to investigate the effects of

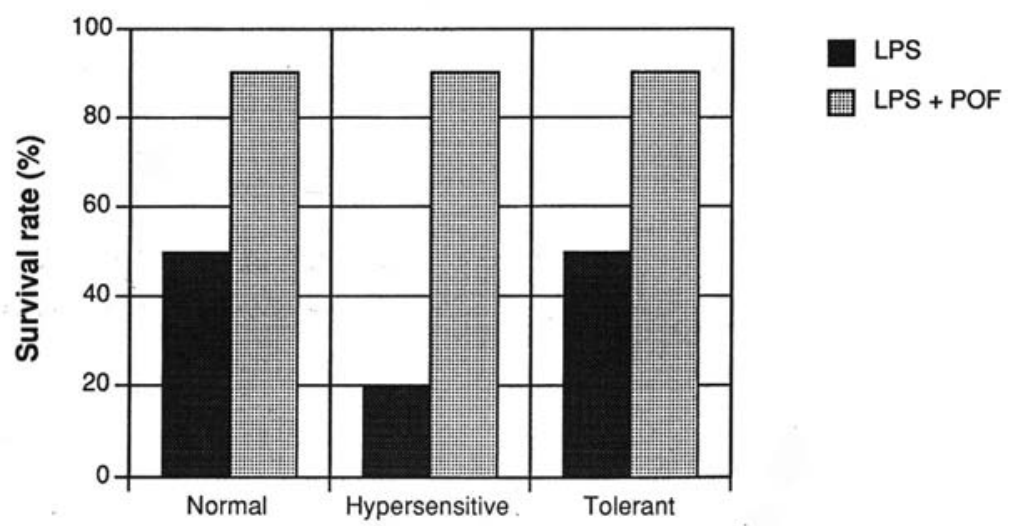

Fig. 3. Protective effect of pentoxifylline $(P O F ; 50 \mathrm{mg} / \mathrm{kg}$ ) on endotoxin (lipopolysaccharide, $L P S)$-induced lethality in normal $(15 \mathrm{mg} / \mathrm{kg})$ LPS-hypersensitive $(6 \mathrm{mg} / \mathrm{kg})$, and LPStolerant $(90 \mathrm{mg} / \mathrm{kg})$ mice 
POF in human volunteers under conditions of controlled endotoxemia [11].

Ten male volunteers (26-38 years old), each of whom had given informed consent before joining the study, were treated with endotoxin and examined on two occasions separated by at least 21 days: endotoxin preparation (sodium salt of LPS from Salmonella abortus equi) was dissolved in isotonic saline and given as a bolus injection (100 ng) intravenously at 8.00 a.m. An intravenous infusion of isotonic saline $(125 \mathrm{ml} / \mathrm{h})$ on the first occasion or POF (500 $\mathrm{mg}$ in $500 \mathrm{ml}$ isotonic saline) on the second occasion was started $30 \mathrm{~min}$ before endotoxin administration and continued for $4 \mathrm{~h}$.

In nine of ten subjects there was a rise in body temperature of at least $1.0^{\circ} \mathrm{C}$, paralleled by an increase in heart rate. The only subject who did not respond to endotoxin weighed more than $95 \mathrm{~kg}$; the endotoxin dose of $100 \mathrm{ng}$ may not have been high enough to induce the typical symptoms. Eight of the remaining nine subjects responded to endotoxin with symptoms such as myalgia and headache, which started 70-100 min after the injection. Two subjects also had nausea (120 min after endotoxin). Systolic and diastolic blood pressure were not affected. None of the clinical responses to endotoxin were affected by POF.

Circulating TNF levels were determined in sera sampled over short time intervals. It was found that a maximum serum level was reached $2 \mathrm{~h}$ postendotoxin (Fig. 4). This increase was statistically significant. At no other time could significant increases in TNF levels be determined. When POF was infused, no increase in TNF levels was observed (Fig. 4). Interleukin-6 (IL-6) serum levels showed a significant increase with its maximum $3 \mathrm{~h}$ after endo-

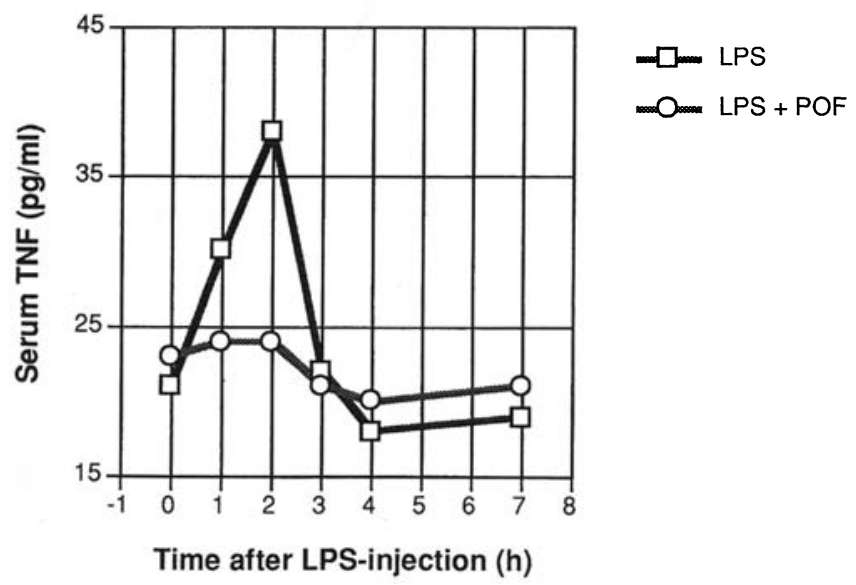

Fig. 4. Effect of pentoxifylline $(P O F ; 500 \mathrm{mg} / 4 \mathrm{~h})$ on circulating tumor necrosis factor $(T N F)$ levels in humans after injection of lipopolysaccharide (LPS; $100 \mathrm{ng})$. TNF levels $2 \mathrm{~h}$ after LPS administration were significantly different between treatment with and without POF 
toxin in comparison to baseline levels. The rise of IL-6 was strictly correlated with the rise of body temperature and appeared $1 \mathrm{~h}$ after TNF peak levels. POF treatment did not affect IL-6 levels after endotoxin administration.

In all subjects the cortisol levels before endotoxin injection were in the normal range. In contrast to the expected slight fall due to the known circadian rhythm, cortisol levels $1 \mathrm{~h}$ after endotoxin were much lower than baseline. This fall was followed by an apparent rise with a peak $4 \mathrm{~h}$ after endotoxin injection, but the levels had reached the normal range of afternoon cortisol levels $7 \mathrm{~h}$ after endotoxin injection. POF treatment did not affect the changes in cortisol levels induced by endotoxin.

In conclusion, we have confirmed the findings of Michie et al. [12] that endotoxin injection in humans leads to a short-term rise in circulating TNF levels. Infusion of POF totally abolished the endotoxin-induced rise in TNF levels. We conclude, therefore, that the lower levels of TNF are due to suppression of its formation by POF. This inhibition was selective for TNF without affecting IL-6 levels. This finding supports the hypothesis that endotoxininduced IL-6 synthesis occurs independently from the preceding TNF synthesis. Also, clinical signs of endotoxemia, such as fever and myalgia as well as high cortisol levels, which are all thought to be provoked by interleukins [13], are not affected by POF treatment. This result suggested distinct regulatory pathways for different cytokines. It is also in agreement with the earlier finding that increases in cellular cAMP selectively suppressed endotoxininduced gene expression in macrophages [14]. This study showed that the positive effects of POF determined in animal models may also apply to the human situation. Although controlled endotoxemia in volunteers differs from septic shock and related clinical conditions, our data provide evidence that POF may also have beneficial effects in these clinical situations.

\section{Pentoxifylline Suppresses OKT3-Induced Tumor Necrosis Factor Formation in Renal Transplant Recipients}

Treatment of allograft transplant recipients with the murine anti-CD3 monoclonal antibody OKT3 leads to a systemic reaction, characterized by chills, fever, nausea, vomiting, diarrhea and sometimes lung edema. Several reports strongly suggested that these side effects are related to the release of cytokines. In particular, TNF seems to play a pivotal role in the pathophysiology of OKT3-induced systemic reactions. It was demonstrated that passive immunization against TNF attenuated the severe side effects of OKT3 in experimental mice [15]. Furthermore, a strong correlation between OKT3 first dose reaction and serum levels of TNF was shown in humans [16]. We, therefore, investigated the efficacy of POF in inhibiting TNF formation and, thus, preventing the severe side effects of OKT3 first dose administration in renal transplant recipients [17].

We studied 16 recipients of a renal allograft during steroid-resistent rejec- 
tion episodes. The diagnosis of rejection was based on clinical and laboratory data and histological findings from fine-needle biopsy. Acute rejection episodes were initially treated with methylprednisolone (MP): $500 \mathrm{mg} /$ day on 4 consecutive days. In the cases where treatment with corticosteroids failed, OKT3 was administered as a daily bolus injection of $5 \mathrm{mg}$ intravenously on at least 5 consecutive days. As recommended by the manufacturer, a single dose of hydrocortisone $(100 \mathrm{mg})$ was administered immediately after the OKT3 first dose injection. Eight patients (controls) were treated with MP $(1 \mathrm{mg} / \mathrm{kg}) 30 \mathrm{~min}$ prior to OKT3. Another group of eight patients (POF group) received an intravenous infusion of POF ( $400 \mathrm{mg}$ in $500 \mathrm{ml}$ isotonic saline) which was started $30 \mathrm{~min}$ before the OKT3 first dose and continued for $3 \mathrm{~h}$.

TNF serum levels increases significantly $2 \mathrm{~h}$ after OKT3 administration in the controls as compared to baseline levels and POF treatment suppressed OKT3-induced TNF formation (Fig. 5). A significant increase of IL-6 levels

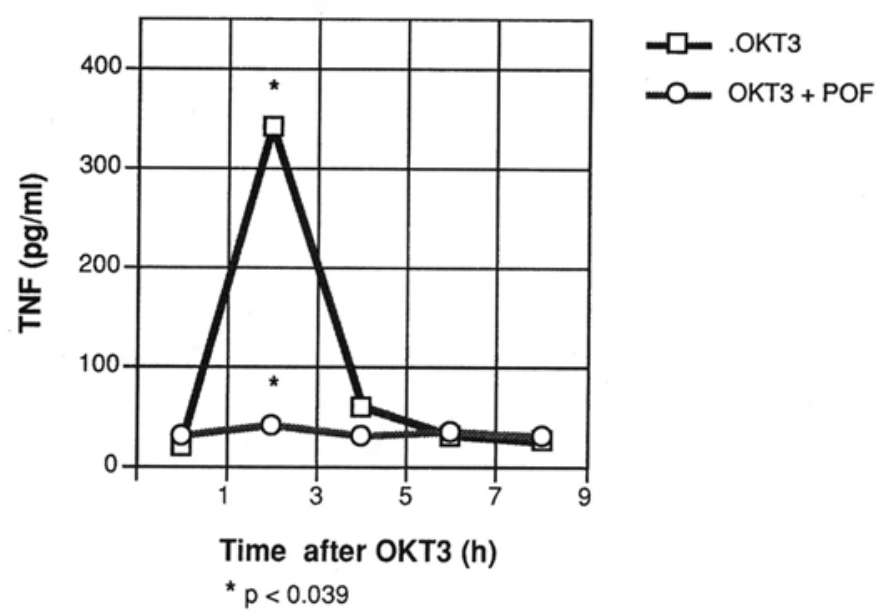

Fig. 5. Effect of pentoxifylline (POF; $1.2 \mathrm{~g} /$ day) on endogenous tumor necrosis factor $(T N F)$ formation in renal transplant recipients after OKT3 first dose injection $(5 \mathrm{mg})$

Table 1. Clinical response to OKT3 first dose administration in renal transplant recipients: effect of pentoxifylline (POF)

\begin{tabular}{lll}
\hline & Controls & POF-treated \\
\hline Fever $>39^{\circ} \mathrm{C}$ & $5 / 8$ & $2 / 8$ \\
Vomiting $/$ diarrhea & $4 / 8$ & $0 / 8$ \\
Dyspnea & $2 / 8$ & $0 / 8$ \\
Headache & $4 / 8$ & $0 / 8$ \\
\hline
\end{tabular}


as compared to baseline levels was found in all patients 4 and $6 \mathrm{~h}$ after OKT3 injection. There were slight but no significant differences in maximal IL-6 values at $6 \mathrm{~h}$ post-OKT3 between controls and POF-treated patients. The same was true for circulating interleukin-8 (IL-8) levels, which reached maximal levels $2 \mathrm{~h}$ after OKT3 injection in all patients, and which also remained unaffected by POF treatment. With respect to the clinical symptoms (Table 1), POF did not abolish the febrile response, although the number of patients developing high grade temperature seemed to be lower in the POF group. Severe side effects of OKT3 first dose, such as gastrointestinal symptoms, headache and dyspnea, were not observed in any patient in the POF group, whereas nearly all of the controls showed at least one of these symptoms. Most importantly, the OKT3-induced reduction of CD3-positive peripheral blood lymphocytes was not influenced by POF, suggesting that POF did not alter the efficacy of the OKT3 therapy.

In conclusion, this pilot trial demonstrated that POF is of potential benefit in OKT3 treatment based on its ability to suppress TNF formation, thus preventing severe clinical side effects. The data of this trial are encouraging and have been confirmed by others $[18,19]$.

\section{Effects of Pentoxifylline on Circulating Cytokines in Severe Pulmonary Tuberculosis}

Tumor necrosis factor has been identified as an important mediator of chronic cachexia in animals and humans [20]. After having shown that POF can reduce both endotoxin and OKT3-induced endogenous TNF formation in humans, we were also interested in its effects on diseases related to cachexia possibly due to chronic release of TNF. Severe pulmonary tuberculosis is associated with systemic reactions, including cachexia, fever and night sweat. These symptoms may be caused by a chronic cytokine release syndrome, in particular, the release of TNF.

Therefore, circulating cytokines were determined in patients with severe pulmonary tuberculosis and systemic reactions under treatment with tuberculostatic agents, and these patients were treated with POF. Patients with a low disease activity and without systemic symptoms served as controls [21].

As shown in Fig. 6, patients with severe pulmonary tuberculosis including systemic reactions (group 1) showed significantly elevated serum TNF levels in comparison to patients with low disease activity without any systemic reaction (group 2). In patients of group 2 serum TNF levels were found at the detection limit of the assay. TNF levels were strictly correlated with the severity of the disease. POF treatment ( $1.2 \mathrm{~g}$ orally/day) of patients in group 1 resulted in an immediate decrease of circulating TNF levels to baseline inducing well-being and a stop of weight loss. IL-6 levels were also significantly increased in patients of group 1 as compared to patients without clinical symptoms (group 2). Patients of group 2 also showed IL-6 levels at the 


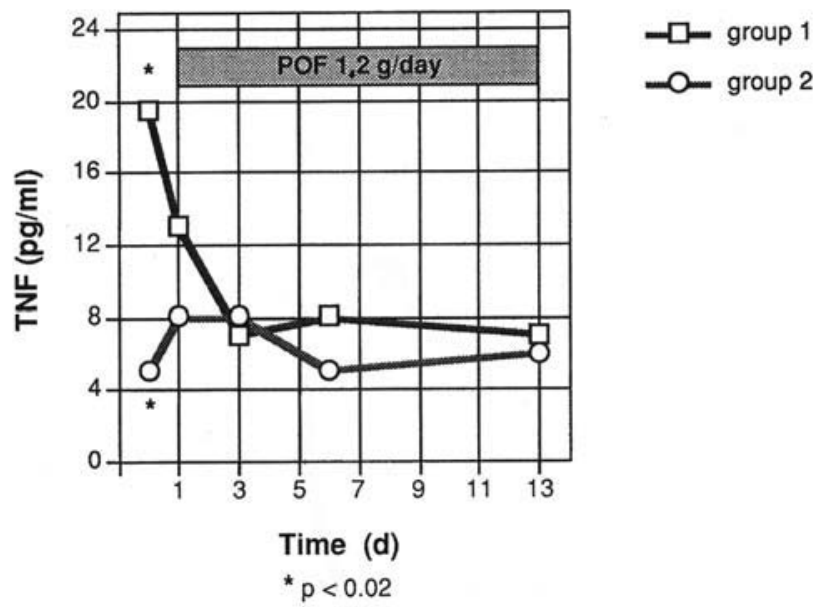

Fig. 6. Modulating effect of pentoxifylline (POF; $1.2 \mathrm{~g} /$ day) on elevated circulating tumor necrosis factor $(T N F)$ levels in patients with severe pulmonary tuberculosis and systemic reactions (group 1 ; squares). Patients with low disease activity without systemic symptoms served as controls (group 2; circles)

detection limit of the assay. POF treatment failed to influence the elevated serum IL-6 levels or the febrile response in patients of group 1.

In conclusion, it was found that severe pulmonary tuberculosis is associated with elevated levels of circulating cytokines (TNF and IL-6). Furthermore, POF treatment inhibited chronic TNF formation selectively, and thus reduced TNF-dependent cachexia without affecting chronic IL-6 formation and related symptoms, such as the febrile response and night sweat.

Table 2. Inhibition of endogenous tumor necrosis factor formation by pentoxifylline: new therapeutic strategies

\begin{tabular}{ll}
\hline Indication & Efficacy \\
\hline $\begin{array}{l}\text { Transplantation } \\
\text { Bone marrow transplant } \\
\text { Renal transplant }\end{array}$ & GVH reaction, vascular leakage syndrome, pneumonitis \\
Septic syndrome & OKT3 side effects, acute renal failure \\
AIDS & Cachexia, virus replication \\
Tumors & Cachexia \\
CNS & \\
Cerebral malaria & Clinical outcome \\
Multiple sclerosis & Disease activity \\
\hline
\end{tabular}




\section{Perspectives}

As shown above, POF is able to attenuate endogenous TNF formation in humans both in experimental and clinical conditions and thus may improve therapeutic strategies in various diseases in which TNF is identified as a pivotal pathophysiological factor (Table 2). Some of these indications have been examined or will be investigated in further clinical studies.

1) In allogenic bone marrow transplantation increased serum levels of TNF precede major complications such as graft-vs-host $(\mathrm{GVH})$ reaction, vascular leakage syndrome and pneumonitis [22]. Preliminary data of a clinical study performed in Seattle (Washington, USA) in patients undergoing allogenic bone marrow transplantation showed that prophylactic administration of POF can prevent major complications and significantly decreases mortality after 1 year of follow-up [23]. In renal transplantation, POF treatment may improve OKT3 therapy as shown above. Furthermore, there is evidence that POF may prevent hypoxia-related changes in the renal function of transplanted kidneys [24].

2) In vivo, POF protected against increased pulmonary vascular permeability and sequestration of neutrophils in the lung of different animal models of acute lung injury [25]. Consequently, as a general outcome, POF was found to improve survival in different models of hemorrhagic [26] and endotoxic shock $[8,27]$. Our data show that these findings from animal models may also apply to human beings [28].

3) Increased TNF levels have been observed in cachectic patients with the acquired immunodeficiency syndrome (AIDS), and TNF is known to increase expression of the human immunodeficiency virus type 1 (HIV-1) by acting on its long terminal repeat. Moreover, TNF was found to decrease the therapeutic efficacy of zidovudine (AZT). POF is able to decrease the replication of HIV-1 in human peripheral blood mononuclear cells and in cultured T cells [29]. Thus, patients with AIDS may benefit from POF treatment because it blocks TNF-mediated HIV-1 up-regulation, potentially increases the efficacy of AZT, and may prevent TNFinduced cachexia.

4) TNF has been implicated as mediator of the severe wasting seen in terminal cancer patients, from which its name cachectin is derived [30]. Recently, it was shown that POF-treated cancer patients experienced an improvement in general well-being accompanied by significant decreases in TNF mRNA levels of peripheral blood monocytes [31].

5) In some diseases of the central nervous system such as cerebral malaria [32] and multiple sclerosis [33], elevated TNF levels in the serum and cerebrospinal fluid correlate with fatal outcome and disease progression, respectively. POF was able to prevent cerebral malaria in Plasmodium berghei-infected mice [34]. In POF-treated mice, TNF in serum was nondetectable, whereas control mice had high TNF levels on day 6 after infec- 
tion. These findings make POF a potential candidate as a supportive agent in human cerebral malaria.

In conclusion, POF is an established drug with no severe side effects and a wide therapeutic range. It may improve therapeutic strategies in cases of acute and chronic cytokine release syndromes by acting as a selective inhibitor of TNF synthesis.

\section{References}

1. Dinarello C (1989) Interleukin 1 and its biologically related cytokines. Adv Immunol 44:153-162

2. Schade FU, Burmeister I, Elekes E, Egel R, Wolter DT (1989) Mononuclear phagocytes and eicosanoids: aspects of their synthesis and biological activities. Blut 59:475479

3. Spengler RN, Spengler ML, Lincoln P, Remick DG, Strieter RM, Kunkel SL (1989) Dynamics of dibutyryl cyclic AMP and prostaglandin E2-mediated suppression of lipopolysaccharide-induced tumor necrosis factor alpha gene expression. Infect Immun 57:2837-2844

4. Porter JM, Cutler BS, Lee BY (1982) Pentoxifylline efficacy in the treatment of intermittant claudication: multicenter controlled double-blind trial with objective assessment of chronic occlusive arterial disease patients. Am Heart J 104:66-72

5. Schade FU (1990) Pentoxifylline increases survival in endotoxin shock and decreases TNF formation. Circ Shock 31:171-181

6. Strieter RM, Remick DG, Ward PA, Spengler RN, Lynch JP, Larrick J, Kunkel SL (1988) Cellular and molecular regulation of tumor necrosis factor-alpha production by pentoxifylline. Biochem Biophys Res Commun 155:1230-1236

7. Waage A, Sorensen M, Stordal B (1990) Differential effect of oxpentyfylline on tumor necrosis factor and interleukin-6 production. Lancet 335:543

8. Schade FU, Schönharting MM (1986) Effect of pentoxifylline on the endotoxininduced shock reaction. Clin Hemorheol 6:462-468

9. Schade FU, von der Bosch J, Schönharting MM (1988) Increase of survival rate by pentoxifylline in endotoxin shock. In: Mandell GL, Nowick WJ (eds) Pentoxifylline and leukocyte function. Hoechst Roussel Pharmaceuticals, Somerville, pp 175-183

10. Schade FU, von der Bosch J, Schönharting MM (1989) Pentoxifylline increases survival of mice in endotoxin shock. In: Schrör K, Sinzinger H (eds) Prostaglandins in clinical research. Liss, New York, pp 223-227

11. Zabel P, Wolter DT, Schönharting MM, Schade UF (1989) Oxpentifylline in endotoxaemia. Lancet 1334:1474-1477

12. Michie HR, Manogue KR, Spriggs DR et al (1988) Detection of circulating tumor necrosis factor after endotoxin administration. N Engl J Med 318:1418-1426

13. Dinarello CA (1987) The biology of interleukin-1 and comparison to tumor necrosis factor. Immunol Lett 16:227-232

14. Tannenbaum CS, Hamilton TA (1989) Lipopolysaccharide-induced gene expression in murine peritoneal macrophages is selectively suppressed by agents that elevate intracellular cAMP. J Immunol 142:1274-1280

15. Ferran C, Sheehan K, Schreiber R, Bach JF, Chatenoud L (1991) Anti-TNF abrogates the cytokine-related anti-CD-3 induced syndrome. Transplant Proc 23:849-854

16. Gaston SG, Deierhoi MH, Patterson T (1991) OKT3 first dose reaction: association with $T$ cell subsets and cytokine release. Kidney Int 39:141-146

17. Zabel P, Leimenstoll G, Schröder P, Elfeldt R, Schlaak M, Niedermayer W (1991) 
Pentoxifylline suppresses OKT3-induced tumor necrosis factor alpha formation in renal transplant recipients. Z Tx Med 3:62-65

18. Schandene P, Vandenbussche P, Crusiaux A et al (1992) Differential effects of pentoxyfylline on the production of tumor necrosis factor-alpha and interleukin- 6 by monocytes and T-cells. Immunology 76:30-34

19. Alegre ML, Gastaldello K, Abromowicz D et al (1991) Pentoxyfylline reduces antiCD3 monoclonal antibodies-induced cytokine release syndrome. Transplantation $52: 674-690$

20. Tracey JK, Lowry SF, Cerami A (1988) Cachectin: a hormone that triggers acute shock and chronic cachexia. J Infect Dis 157:413-420

21. Zabel P, Greinert U, Entzian P, Schlaak M (1992) Effects of pentoxifylline on circulating cytokines (TNF and IL-6) in severe pulmonary tuberculosis. Eur Cytokine Network $3: 248 \mathrm{~A}$

22. Holler E, Kolb HJ, Möller A et al (1990) Increased serum levels of tumor necrosis factor $\alpha$ precede major complications of bone marrow transplantation. Blood 75:10111016

23. Bianco AJ, Appelbaum FR, Nemunaitis J et al (1991) Phase I-II trial of pentoxyfylline for the prevention of transplant-related toxicities following bone marrow transplantation. Blood 78:1205-1211

24. Berens KL, Luke DR (1990) Pentoxifylline in the isolated perfused rat kidney. Transplantation 49:876-879

25. Welsh CH, Lien D, Wothen GS, Weil JV (1988) Pentoxifylline decreases endotoxininduced pulmonary neutrophil sequestration and extravascular protein accumulation in the dog. Am Rev Respir Dis 138:1106-1114

26. Coccia MT, Waxman K, Soliman MH, Tominaga G. Pinderski L (1989) Pentoxifylline improves survival following hemorrhagic shock. Crit Care Med 17:36-38

27. Schönharting MM, Schade FU (1989) The effect of pentoxifylline in septic shock - new pharmacological aspects of an established drug. J Med 20:97-105

28. Zabel P, Schönharting MM, Schade FU, Schlaak M (1991) Effects of pentoxifylline in endotoxaemia in human volunteers. In: Sturck A (ed) Bacterial endotoxins, cytokine mediators and new therapies for sepsis. Wiley-Liss, New York, pp 207-213

29. Fazely F, Dezube BJ, Allen-Ryan J, Pardee AB, Ruprecht RM (1991) Pentoxifylline (Trental) decreases the replication of the human immunodeficiency virus type 1 in human peripheral blood mononuclear cells and in cultured T-cells. Blood 77:1653-1656

30. Beutler B, Cerami A (1987) Cachectin: more than a tumor necrosis factor. N Engl J Med 316:379-382

31. Dezube BJ, Fridovich-Keil JL, Bouvard I, Lange RF, Pardee AB (1990) Oxpentifylline and well being in patients with cancer. Lancet 335:662

32. Kern P, Hemmer CJ, von Damme J, Gruss HJ, Dietrich M (1989) Elevated tumor necrosis factor alpha and interleukin-6 serum levels as markers for complicated Plasmodium falciparum malaria. Am J Med 87:139-143

33. Sharief MK, Hentges R (1991) Association between tumor necrosis factor alpha and disease progression in patients with multiple sclerosis. N Engl J Med 325:467-472

34. Kremsner PG, Grundmann H, Neifer S, Sliwa K, Sahlmüller G, Hegenscheid B, Blenzie U (1991) Pentoxyfylline prevents murine cerebral malaria. J Infect Dis 164:605608 